\title{
The significance of plasma phytanic acid levels in adults
}

\author{
T C BRITTON, F B GIBBERD, M E CLEMENS, J D BILLIMORIA, M C SIDEY
}

From the Departments of Neurology and Lipid Biology, Westminster Hospital, London UK

SUMMARY The presence of phytanic acid in tissues and plasma has been considered diagnostic of heredopathia atactica polyneuritiformis (Refsum's disease), but recently slightly raised plasma phytanic acid levels have been reported in other conditions. Forty two normal people were found to have a phytanic acid level of $0-33 \mu \mathrm{mol} / \mathrm{l}$. Fourteen patients with heredopathia atactica polyneuritiformis had a plasma phytanic acid level before treatment of $992-6400 \mu \mathrm{mol} / \mathrm{l}$. Five patients with retinitis pigmentosa but not heredopathia atactica polyneuritiformis had plasma levels of 38$192 \mu \mathrm{mol} / \mathrm{l}$. It was concluded that some patients with retinitis pigmentosa without heredopathia atactica polyneuritiformis but a raised plasma phytanic acid may represent a group of patients with a disease or diseases as yet uncharacterised apart from the retinal condition.

Phytanic acid $(3,7,11,15$ tetramethylhexadecanoic acid) is a normal constituent of food and is found particularly in the fat of ruminant animals and in dairy products. ${ }^{\prime}$ Unlike other naturally occurring fatty acids, phytanic acid cannot be metabolised by betaoxidation because the methyl side chains block the enzymatic action; an initial alpha-oxidation is necessary for its catabolism. ${ }^{1}$ As a result of a specific defect in alpha-oxidation in patients with heredopathia atactica polyneuritiformis (HAP) (Refsum's disease) ${ }^{2}$ phytanic acid accumulates in large amounts in their tissues and plasma. ${ }^{3}$ The disease is characterised by retinitis pigmentosa, ataxia and polyneuropathy ${ }^{4}$ and in addition there may be anosmia, sensorineural hearing loss, ichthyosis and cardiac abnormalities. At the time of diagnosis patients with HAP usually have plasma phytanic acid levels above $800 \mu \mathrm{mol} / \mathrm{l}^{5}$ while normal people have been considered to have undetectable levels.

Recently abnormalities in the fatty acids including moderately raised phytanic acid levels have been reported in several childhood conditions ${ }^{6}$ including Zellweger's syndrome, adrenoleukodystrophy, infantile Refsum's syndrome and pipecolic acidaemia. ${ }^{7-12} \mathrm{~A}$ plasma phytanic acid level as high as $320 \mu \mathrm{mol} / 1$ was found in one case of adrenoleukodystrophy. ${ }^{6}$ The plasma levels of other fatty acids are also abnormal in

Address for reprint requests: Dr F B Gibberd, Westminster Hospital, London SW1P 2AP, UK.

Received 14 October 1988 and in revised form 30 December 1988. Accepted 10 January 1989 these conditions. In some of these children there is a more general abnormality in the number of peroxisomes in the skin fibroblasts and therefore this group of conditions, in none of which is the biochemical abnormality confined to a defect of phytanic acid metabolism, has been termed the peroxisomal disorders. ${ }^{13}$

The significance of plasma phytanic acid levels in adults is uncertain. Although very high levels of plasma phytanic acid are diagnostic of HAP, ${ }^{314}$ the interpretation of lower levels is more difficult. The level of phytanic acid in the plasma of patients with HAP varies considerably ${ }^{6}$ as it rises when the disease worsens and may fall to very low levels with treatment. ${ }^{515}$ Low levels of phytanic acid have been detected in relatives of patients with HAP.

\section{Methods}

Forty two hospital inpatients were studied: 37 preoperative orthopaedic patients and five general medicine patients. Their consent was obtained and venous blood taken on two occasions; first in the afternoon as a random non-fasting sample and the second in the morning after at least an 8 hour fast. Information about age, sex, medication, major illnesses and smoking habits was obtained. None suffered from HAP. The blood was analysed for fasting lipids and fasting and non-fasting plasma phytanic acid. The presenting plasma phytanic acid levels of the 14 patients with HAP who have attended Westminster Hospital are given for comparison. A group of patients with neurological or ophthalmic abnormalities who had previously been identified because of slightly raised phytanic acid was reviewed.

Cholesterol, triglyceride and high density lipoprotein were 
estimated using routine laboratory methods (Technicon autoanalyser 11). ${ }^{16}$ Plasma phytanic acid was estimated by gas-liquid chromatography (GLC) analysis of the methyl esters as previously described ${ }^{17}$ with the modification that instead of a $1.5 \mathrm{~m}$ glass column packed with $10 \%$ polyethyleneglycol adipate (PEGA), a 12 metre BP10 fused silica column (internal diameter $0.25 \mathrm{~mm}$, using an oven temperature of $170^{\circ} \mathrm{C}$ and carrier gas inlet pressure of $41 \mathrm{kpa}$ Hydrogen), obtained from Scientific Glass Engineering was used. The modification made no difference to the numerical results but improved the separation from other fatty acids. The $\log$ retention value of methyl ester of phytanic acid relative to methyl pentadecanoic acid under these conditions was 0.473 (SD 0.002). The limit of detection of phytanic acid was $3 \cdot 2 \mu \mathrm{mol} / 1$.

\section{Results}

Normal Controls. Of the 42 patients, 15 were male and 27 female, eight were aged between 16 and 30 years, 14 between 30 and 60 and 20 were over 60 years. Five patients had abnormal lipid profiles. The plasma phytanic acid levels ranged from zero (that is, less than $3.2 \mu \mathrm{mol} / \mathrm{l})$ to $33 \mu \mathrm{mol} / 1$ although most samples contained less than $22 \mu \mathrm{mol} / \mathrm{l}$. The distribution is shown in figs 1 and 2 . Undetectable levels occurred in both fasting and non-fasting subjects but not always in the same person.

The means for the fasting and non-fasting levels in these normal persons were $7 \cdot 7 \mu \mathrm{mol} / 1$ and $8.3 \mu \mathrm{mol} / 1$. Because of the large number of results at unrecordable levels a normal distribution was not obtained and a

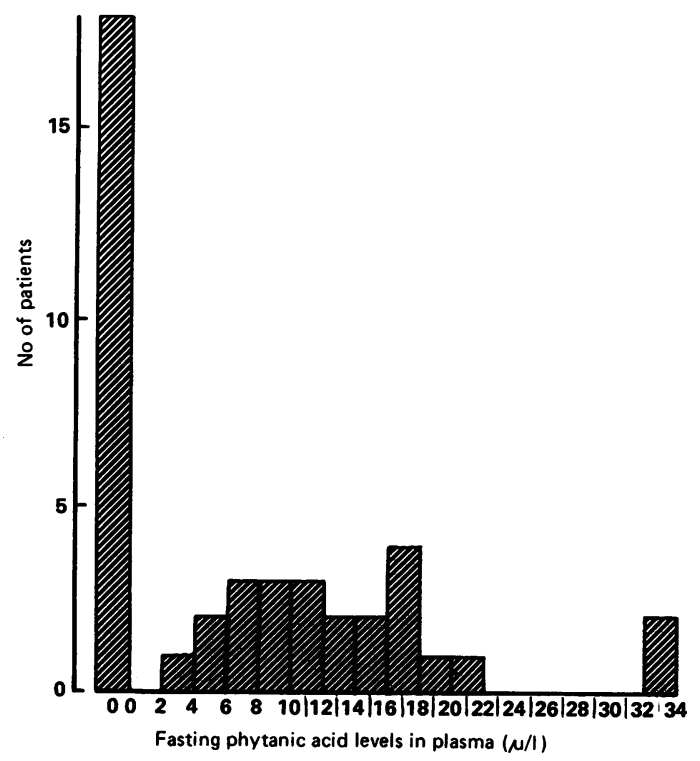

Fig 1 Distribution of plasma phytanic acid levels in control subjects: Fasting.

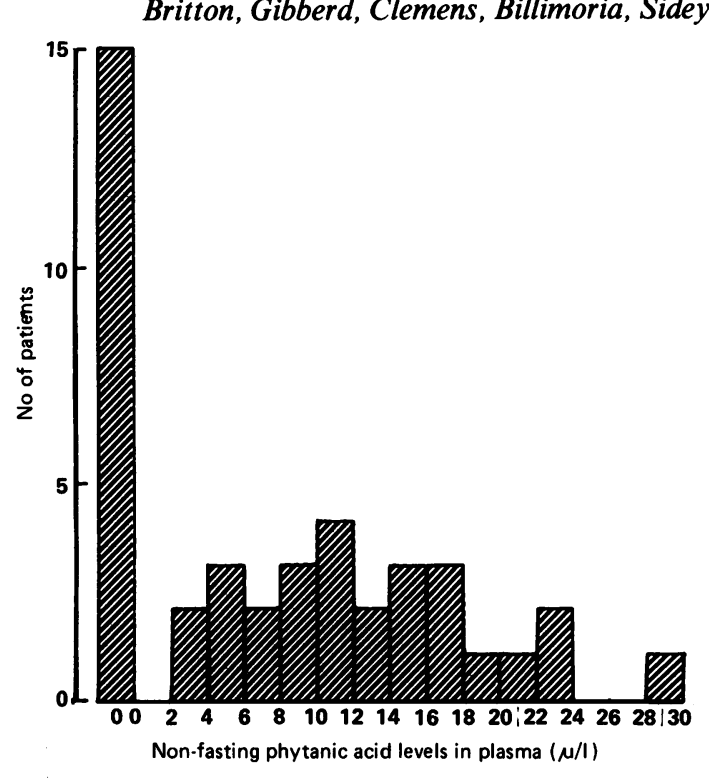

Fig 2 Random non-fasting distribution of plasma phytanic acid levels in control subjects.

standard deviation would be unhelpful. The normal level would be better expressed as saying the 950 percentile lies below $22 \mu \mathrm{mol} / 1$ for fasting and $24 \mu \mathrm{mol} / /$ 1 for non-fasting subjects. There was no differenceshown between males and females, between younger and older adults or between those with normal and abnormal lipid profiles.

The initial plasma phytanic acid level in the 14 patients with HAP seen at Westminster Hospital prior to the commencement of dietary treatment ranged between 992 and $6400 \mu \mathrm{mol} / 1$ (mean $2151 \mu \mathrm{mol} / \mathrm{l}$ ). After treatment the levels fell in all patients to between 16 and $1060 \mu \mathrm{mol} / 1$ (mean of $310 \mu \mathrm{mol} / \mathrm{l}$ ). The plasma phytanic acid levels of the group of adult patients on a normal diet with slightly raised phytanic acid levels, retinitis pigmentosa and other neurological disorders, but not HAP are given in table 1 . The levels ranged from 38 to $192 \mu \mathrm{mol} / \mathrm{l}$.

Table 1 Raised phytanic acid levels in patients with retinitis pigmentosa but not heredopathia atactica polyneuritiformis in $\mu \mathrm{mol} / \mathrm{l}$

\begin{tabular}{lllc}
\hline & Patient & Other clinical findings & $\begin{array}{l}\text { Phytanic } \\
\text { acid }\end{array}$ \\
\hline 1. & WAD & Anosmia & $38 \cdot 4$ \\
2. & PB & Anosmia & $54 \cdot 4$ \\
3. & JF & Anosmia & 48 \\
4. TR & Deafness ataxia & 86.4 \\
5. & OS & Deafness & 192 \\
\hline
\end{tabular}

The results given are the means of several readings. 


\section{Discussion}

The presence of trace amounts of phytanic acid in a normal population has been reported previously ${ }^{1418}$ but the normal range has never been defined. Avigan ${ }^{14}$ measured the phytanic acid in a pooled sample of sera from 200 non-fasting healthy male blood donors and obtained a value of $6.4 \mu \mathrm{mol} / 1$ for phytanic acid, a figure which is close to the average found in this study. In the three individual samples measured the level was 1.3 to $6.4 \mu \mathrm{mol} / 1 .{ }^{14} \mathrm{Kremer}^{18}$ reported the phytanic acid levels to vary between 0.2 and $0.6 \%$ of total lipids which is a test not directly comparable, as the total lipid levels were not stated. Two other workers have separately attempted to measure phytanic acid levels in controls. Try ${ }^{19}$ found the phytanic acid not raised in the plasma of 73 patients who had retinitis pigmentosa or a neurological disorder, but the limit of detection of the assay was only $64 \mu \mathrm{mol} / 1$ and Poulos ${ }^{20}$ found all 50 of his controls to have less than $16 \mu \mathrm{mol} / 1$ which was the limit of detection of his assay.

The method of assay used in the present study is similar to previous methods, but a different column was used. Previously ${ }^{21}$ the use of traditional polar and non-polar packed columns such as PEGA and APL ('Apiezon-L') for the analysis of phytanic acid caused problems because on PEGA phytanic acid coelutes with margaric acid and on APL with unsaturated 18 carbon fatty acids such as oleic acid. The capillary column used in the present study is only slightly polar and separates phytanic acid from all other fatty acids and thus ensures an accurate analysis. The shape of the peaks obtained with the capillary column is such that automatic integrators are less likely to miscalculate the areas.

This study has shown that:

(1) Using sensitive techniques phytanic acid can be measured in small amounts in the plasma of some normal people.

(2) Phytanic acid levels can vary in the same normal individual being undetectable at some times and measurable at others.

(3) There is no significant difference between 8 hour fasting and non-fasting levels of phytanic acid in the normal person.

(4) Age, sex and abnormal lipid profiles do not affect phytanic acid levels in the normal population.

(5) Phytanic acid levels in $95 \%$ of normal individuals are less than $22 \mu \mathrm{mol} / 1$ and any level above $33 \mu \mathrm{mol} / 1$ should be considered abnormal.

Five patients who have retinitis pigmentosa and some but not all the features of HAP had plasma phytanic acid levels above, but not greatly above, the maximum normal level of $33 \mu \mathrm{mol} / 1$. A markedly raised phytanic acid is not a feature of patients with retinitis pigmentosa unless they also have $\operatorname{HAP}^{22}$ (see

Table 2 Plasma phytanic acid in $\mu$ mol/l summary of levels found in clinical practice

Normal person

Heterozygote for H.A.P. gene

Peroxisomal diseases

Patient with H.A.P. treated for over one year

Untreated patient with H.A.P.

table 2). However none of these five patients had a plasma level sufficiently elevated to be comparable with the initial plasma phytanic acid levels of the 14 patients with HAP. These five patients may be suffering from a syndrome independent of HAP, which is associated with a mild rise in the phytanic acid level in the blood.

Using the techniques described in this paper and having defined a normal limit for the plasma phytanic acid it should now be possible to distinguish a group of adults who are not relatives of patients with HAP and therefore possible carriers of a gene for HAP but who have unelucidated conditions which are not infantile peroxisomal disorders but which cause slight elevation of phytanic acid levels. In summary, for patients with recognised syndromes the plasma phytanic acids which may occur are given in table 2 . The five patients in table 1 would not conform to one of the recognised groups and could represent a separate entity.

We thank the Retinitis Pigmentosa Society for a Research grant in aid of this work.

\section{References}

1 Steinberg D. Phytanic acid storage disease (Refsum's disease). In: Stanbury JB, Wyngarden JB, Fredricksen DS, Goldstein JL, Brown MS, eds. The Metabolic Basis of Inherited Disease. New York: McGraw Hill, 1983:731-47.

2 Stokke O, Try K, Eldjarn L. Alpha oxidation as an alternative pathway for the degradation of branch-chained fatty acids in man, and its failure in patients with Refsum's disease. Biochim Biophys Acta 1967;144:271-84.

3 Klenk E, Kahlke W. Uber das Vorkommen der 3, 7, 11, 15-Tetra methylhexadecansaure (Phytansaure) in den Cholesterinestern und anderen Lipoidfraktionen der organe bei einem Krankheitsfall unbekhannter Genese (Verdacht auf Heredopathia atactica polyneuritiformis <Refsum-Syndrom >). Hoppe-Seyler Zeits Physiol Chem 1963;333:133-9.

4 Refsum S. Heredopathia Atactica Polyneuritiformis: A familial syndrome not hitherto described. A contribution to the clinical study of the hereditary disorders of the nervous system. Acta Psychiatr Scand 1946; Supplement 38.

5 Gibberd FB, Billimoria JD, Goldman JM, et al. Heredopathia atactica polyneuritiformis: Refsum's Disease. Acta Neurol Scand 1985;72:1-17.

6 Skjedal OH, Stokke O, Refsum S, Norseth J, Petit H. Clinical and biochemical heterogeneity in conditions with phytanic acid accumulation. J Neurol Sci 1987;77:87-96.

7 Scotto JM, Hadchouel M, Odievre M, Laudat M-H, Saudubray JM, Dulac O, Beucler I, Beaune P. Infantile phytanic acid storage disease, a possible variant of Refsum's disease: Three cases 
including untrastructural studies of the liver. $J$ Inher Metab Dis 1982;5:83-90.

8 Poulos A, Pollard AC, Mitchell JD, Wise G, Mortimer G. Patterns of Refsum's Disease. Arch Dis Child 1984;59:222-4.

9 Poulos A, Sharp P, Whiting M. Infantile Refsum's disease (phytanic acid storage disease): a variant of Zellweger's syndrome? Clin Genet 1984;26:579-86.

10 Weleber RG, Tongue AC, Kennaway NG, Budden SS, Baist NRM. Ophthalmic manifestations of Infantile Phytanic acid storage disease. Arch Ophthalmol 1984;102:1317-21.

11 Dotti MT, Rossi A, Rizzuto N, Hayek G, Bardelli N, Bardelli AM, Federico A. Atypical phenotype of Refsum's disease: Clinical, biochemical, neurophysiological and pathological study. Eur Neurol 1985;24:85-93.

12 Budden SS, Kennaway NG, Buist NRM, Poulos A, Weleber RG Dysmorphic syndrome with phytanic acid oxidase deficiency, abnormal very long chain fatty acids, and pipecolic acidaemia: studies in four children. $J$ Pediatr 1986;108:33-9.

13 Moser HW. Peroxisomal Disorders. J Pediat 1986;108:89-91.

14 Avignan $\mathrm{J}$. The presence of phytanic acid in normal human and animal plasma. Biochim Biophys Acta 1966;116:391-4.

15 Stokke O, Skjeldal OH, Hoie K. Disorders related to the mechanism of phytanic acid. Scand J Clin Lab Invest 1986;46: Suppl 184:3-10.

16 Burstein M, Samaille J. Sur un dosage rapide du cholesterol lie aux alpha- et aux beta-lipoproteines du serum. Clin Chim Acta 1960;5:609.

17 Gibberd FB, Billimoria JD, Page NGR, Retsas S. Heredopathia Atactica Polyneuritiformis treated by diet and plasma exchange. Lancet 1979;i:575-8.

$18 \mathrm{Kremer}$ GJ. Uber das Vorkommen der 3, 7, 11, 15-Tetramethylhexadecansaure in den Lipoiden von Normalseren. Klin Wochenschr 1965;43:517-8.

19 Try K. Heredopathia Atactica Polyneuritiformis (Refsum's Disease). The diagnostic value of phytanic acid determination in serum lipids. Eur Neurol 1969;2:1-19.

20 Poulos A. Diagnosis of Refsum's disease using [1-14C] phytanic acid as a substrate. Clin Genet 1981;20:247-53.

21 Masters-Thomas A, Bailes J, Billimoria JD, Clemens ME, Gibberd FB, Page NGR. HeredopathAtactica Polyneuritiformis (Refsum's disease) 1. Clinical features and dietary management.
J Human Nutr 1980;34:245-50.

22 Goldman JM, Clemens ME, Gibberd FB, Billimoria JD. Screening of patients with retinitis pigmentosa for heredopathia atactica polyneuritiformis (Refsum's disease). $\mathrm{Br}$ Med $\mathrm{J}$ 1985;290:1109-10.

\section{Appendix}

Figures used for histograms

\begin{tabular}{lcc}
\hline $\begin{array}{l}\text { Plasma phytanic } \\
\text { acid in umol/l }\end{array}$ & Fasting & Non-fasting \\
\hline 0 & 18 & 15 \\
$0-2$ & 0 & 0 \\
$2-4$ & 1 & 2 \\
$4-6$ & 2 & 3 \\
$6-8$ & 3 & 2 \\
$8-10$ & 3 & 3 \\
$10-12$ & 3 & 4 \\
$12-14$ & 2 & 2 \\
$14-16$ & 2 & 3 \\
$16-18$ & 4 & 3 \\
$18-20$ & 1 & 1 \\
$20-22$ & 1 & 1 \\
$22-24$ & 0 & 2 \\
$24-28$ & 0 & 0 \\
$28-30$ & 0 & 1 \\
$30-32$ & 0 & 0 \\
$32-34$ & 2 & 0 \\
Total & 42 & 42 \\
\hline
\end{tabular}

Conversion factors for phytanic acid

Molecular weight $=312$

$1 \mathrm{mg}=3.21 \mu \mathrm{mol}$

$1 \mathrm{mg} / 100 \mathrm{ml}=32 \cdot 1 \mu \mathrm{mol} / 1$

$1 \mu \mathrm{mol}=0.312 \mathrm{mg}$

$1 \mu \mathrm{mol} / 1=0.0312 \mathrm{mg} / 100 \mathrm{ml}$ 